\title{
北师港浸大质量保障体系的建设和实践
}

\section{Implementing Robust Quality Assurance System}

\author{
李建会 Li Jianhui*
}

北京师范大学-香港浸会大学联合国际学院 ( 简称 “北师港 浸大”，英文简称 “UIC” ）由北京师范大学和香港浸会大学于 广东省珠海市携手创立于 2005 年, 是内地与香港参照《中外合作 办学条例》合办的第一所大学, 是粤港澳大湾区高等教育合作的 先锋。质量是大学教育的生命。中外合作大学的特色就是把中外 大学先进的办学经验结合在一起, 形成一个以质量为核心的新的 质量保障体系。北师港浸大自2005年创办至今一直把质量放在首 位, 形成了以两所母体大学的定期评审等机制为特色的外部保障 体系, 以及以北师港浸大自身特色的质量保障为内容的内部质量 保障体系。两种质量保障机制相互结合, 实现了北师港浸大办学 质量水平和层次的提升, 成为粤港澳大湾区高等教育合作的成功 典范之一。本文为2019年3月21日, 笔者在2019年广东省本科高校 教学工作会议上所做的报告。

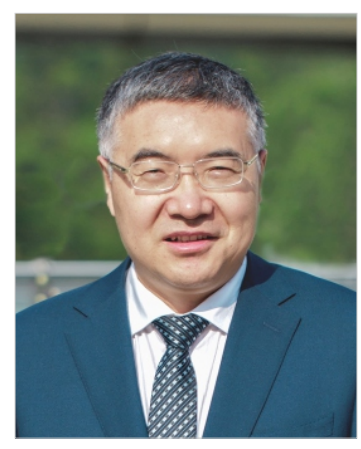

*李建会教授, 北师港浸 大教务长, 研究拓展及 知识转移处副处长。

Prof Li Jianhui, UIC's Academic Registrar, Deputy Director of Research Development and Knowledge Transfer Office

$\mathrm{O}$ $\mathrm{NE}$ of the main keys for university education is quality. The Sino-foreign/Mainland-SAR cooperative universities integrate the experiences of both sides and form unique Quality Assurance Systems. Since its inception in 2005, UIC has always placed quality as the top priority. UIC's Quality Assurance System features regular external reviews by UIC's parent institutions, namely Beijing Normal University and Hong Kong Baptist University, as well as implementing a strict internal mechanism.

This Quality Assurance System has boosted UIC to great improvement and to a high quality level, allowing UIC to become one of the successful examples of higher education cooperation in the Guangdong-Hong Kong-Macao Greater Bay Area. This article is presented at a teaching and learning conference of undergraduate education in Guangdong Province on 21 March 2019. 


\section{一、北师港浸大的办学成就}

质量是大学教育的生命线, 作为内地和 香港合办的第一所大学, 自成立之日起, 就 坚持把本科教育作为核心，把教学质量放在

回顾14年的办学历程，下面这些成就可 以说是具有里程碑的意义: 建校第三年 （2008），时任广东省委书记、中共中央政 治局委员汪洋莅临视察, 并对学校的办学成 绩给予高度评价; 办学第四年 (2009)，一 本招生扩大至16个省市自治区; 办学第五年 （2010），北师港浸大诞生首位剑桥硕士, 并迎来首批法国交换生; 办学第六年 （2011），诞生首位牛津硕士，并与美国明 尼苏达州私立大学协会 (MPCC) 签订“合 作备忘录”；办学第七年 (2012)，首次颁 授荣誉院士，与珠海市政府、横琴新区建立 战略合作关系; 办学第八年 (2013)，在广 东省实施招生改革, 采取多元化的招生录取 模式，同时在全国其他招生地区全部实现了 一本招生; 办学第九年 (2014)，新校园奠 基; 办学第十一年 (2016)，获教育部批准 正式开展研究生教育; 办学第十二年 （2017），新校园正式启用, 研究生院建
立; 办学第十四年（2019），中国科学院院 土汤涛教授担任北师港浸大第二任校长, 珠 海市迎来首个全职工作的院士。

本科教育一直是北师港浸大的核心， 14年来, 本科教育的水平不断提升, 毕业生 质量不断的提高。到2018年, 北师港浸大的 出国/出境深造毕业生有811人, 占本届毕业 生总数的 $67.92 \%$, 其中有 481 名学生进入 QS 排名前百名的世界名校, 占出国深造人数 的近 $60 \%$, 名列广东省升学率的第一名。

北师港浸大之所以能在这么短的时间内 取得这样的成就，一个主要的原因就是北师 港浸大建立了一套有自己独特特征的教学质 量保障体系。

\section{二、北师港浸大的内部质量保障体系}

北师港浸大的质量保障体系包括内部质 量保障和外部质量保障两部分。内部质量保 障包括独特的管理模式，国际化的师资队 伍, 严格的专业评审, 博雅型的课程设计, 高质量的生源, 高品质的教学, 以学生为本 的导师关顾计划, 丰富的校园文化, 以及良 好的条件支撑系统，等等。

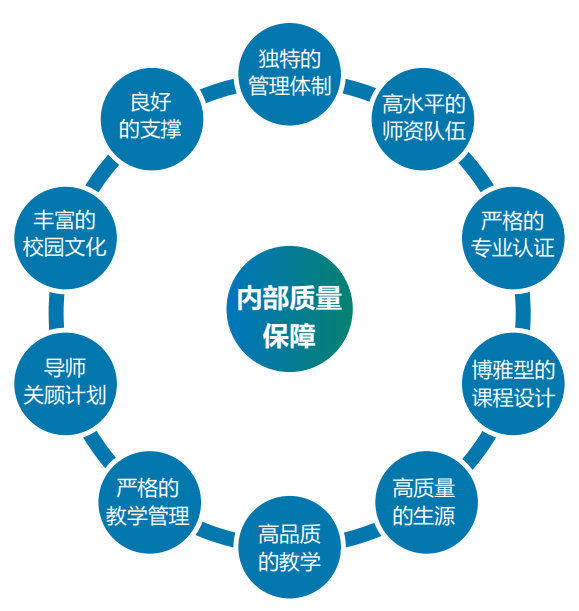




\section{1. 国际化的管理模式}

大学的管理模式是高校人才培养质量保 障的一个重要方面。北师港浸大实行的是国 际上通行的校董会领导下的校长负责制。校 董会由北京师范大学和香港浸会大学各5位 代表组成。校董会一般情况下每学期召开一 次会议, 对学校发展中的重大问题进行审 议, 并做出决定。校长由校董会通过全球招 聘任命, 校长对学校的学术和行政事务负 责。学校除了一般的学术和行政机构之外, 还设有各种委员会, 委员会一般由各个学科 的教授组成。学校的重大事项一般都要通过 各种委员会做出最终决定。其中教务议会和 校务委员会是学校的两个最重要的委员会, 分别审议学校的重大学术事务和行政事务。 两个委员会下面设有与不同的学术和行政相 关的各种委员会，比如教务议会下面设有： 学术发展委员会、质量保障委员会、研究生 学习和科研委员会、学生纪律委员会、学生 申诉委员会等等; 校务委员会下设学校健康 和安全委员会、教师和职员事务委员会、行 政事务执行委员会、财经委员会、信息技术 委员会、国际事务委员会等等。

\section{2. 国际化的教师队伍}

高水平的教师是教学质量保障的最重要 因素, 因此, 北师港浸大非常重视教师队伍 的建设。北师港浸大按照香港浸会大学的标 准及程序进行全球招聘教师。学校现有师资 来自三十多个国家和地区, 以教学为主, 兼 顾研究与服务。学校现有教职员工 868 人, 其中教学人员 428 名。428名教师中，31\%的

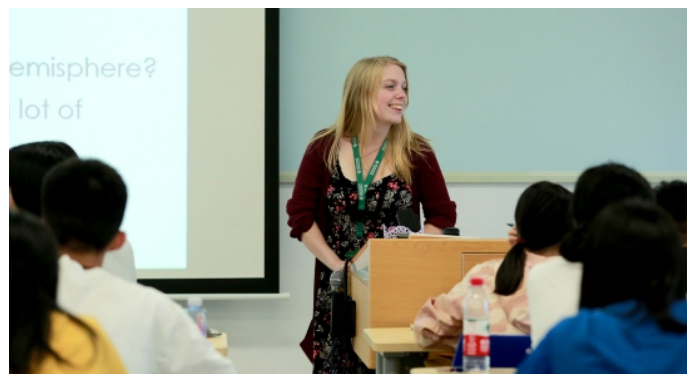

北师港浸大约三成教师来自国外

来自国外，34\%的来自港澳台，35\%的来自 内地（数据统计截止至2019年3月）。讲师 以上职称的教师大都是毕业于国外或香港名 校的博士，尤其是新引进的专任教师。

\section{3. 严格的、国际化的专业评审体系}

专业是开展本科教育的学科平台。良好 的专业可以吸引到更加优秀的生源。北师港 浸大非常重视本科专业的建设, 所有专业从 计划建立到最终获批招生, 都要经过严格的 和国际化的专业评审。专业的发展首先由学 部的专业规划团队提出新增专业计划, 然后 由学部的专业管理委员会讨论, 再提交学部 委员会讨论; 通过后, 上报学校的学术发展 委员会讨论, 发展委员会如果认为专业规划 和建设可行, 再报学校的质量保障委员会, 对学科专业现有的师资和质量保障进行讨 论, 通过后, 提交学校的教务议会讨论。教 务议会通过后, 提交香港浸会大学的质量保 障委员会讨论表决, 最后提交香港浸会大学 教务议会讨论和表决。北师港浸大也需要把 专业申请材料提交北京师范大学进行评审。 如果两个母校通过, 学校把相关学科的申请 资料上报教育部评审和备案, 备案通过后, 该专业方可在全国招收学生。 


\section{4. 国际化的博雅型课程结构}

教学质量保障的核心部分是课程的设 置和课程的教学。北师港浸大根据香港浸会

指导的课程结构。博雅教育的目标是培养既 具有广博的知识、学问、能力, 又具有良好 的道德修养和服务意识, 身体健康、人格完 整的创新型、领袖型、服务型高层次人才。 因此学校设计了专业教育与通识教育、全人 教育以及国情国学教育相结合的课程体系。 专业教育包括专业核心课程、专业选修课程 和自由选修课程。专业核心课程42学分, 专业选修课程18学分, 主要学习专业的基 础知识和专业发展的知识。自由选修课可以 选择本专业的课程, 也可以选择其他专业的 课程。其中, 如果自由选修课程和专业选修 课程选择得当, 学生除获得主修专业的证书 之外, 还可以获得一个副修专业的学习 证书。

\begin{tabular}{|l|c|}
\hline 课程类别 & 学分 \\
\hline 专业核心课 & 42 \\
\hline 专业选修课 & 18 \\
\hline 通识教育核心课 & 32 \\
\hline 通识教育分类选修课 & 12 \\
\hline 全人教育体验学习课程 & 4 \\
\hline 自由选修课 & 24 \\
\hline 合计 & 132 \\
\hline
\end{tabular}

国情国学教育目的是培养学生了解中国 国情和中国传统文化, 心系中华, 胸怀世 界。目前开设了中国传统思想的现代诠释、 百年中国、中国文化经典解读、中国传统文
化欣赏（音乐、诗歌等）等课程, 另外还通 过举办国情国学研讨会、中国文化创意大 赛、国情国学研习营、中华义理大讲堂等活 动, 增强学生对国情国学的了解。

全人教育（简称WPE），又称全面教育， 关注每个学生的智力、道德、体能、社交、 情感、审美和精神潜质的提升。旨在帮助学 生塑造性格、广泛学习社会知识及技能、养 成独立思考能力和解决个人问题的能力、形 成崇高的道德意识和社会意识。通过设置一 系列体验式学习模块来发展北师港浸大全人 教育课程。主要课程包括: 情绪智能、体育 文化、艺术体验、义工服务、环境意识和逆 境管理等。每个课程一学分, 学生需要选修 四门课程。

\section{5. 高质量的生源}

高质量的生源是高质量人才培养的基 础。吸引并招收高质量的生源对北师港浸大 来说是头等大事。学校高度重视招生工作, 校长亲自抓招生, 全校教师参与招生。学校 还通过各种形式 (比如, 举办全国各地重点 中学校长论坛、家长论坛、全国重点地区和 重点中学宣讲会, 等等), 建立遍布全国的

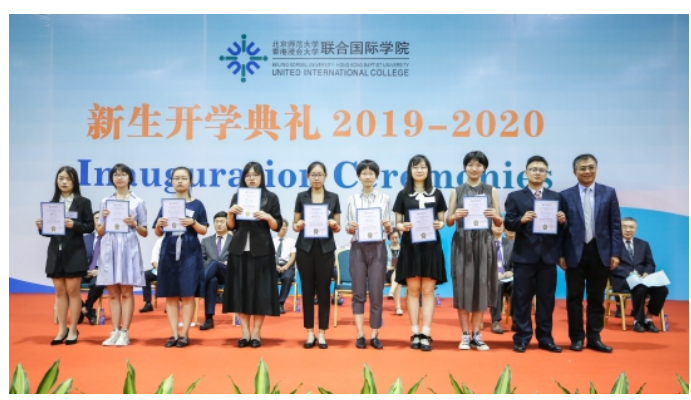

汤涛校长在开学典礼为获新生入学奖学金的 同学颁发荣誉证书 
招生网络。目前学校实现了在全国招生地区 一本招生, 在广东省实现了多元化的招生改 革。广东省的考生一方面可通过参加自主招 生考试, 按照 “631” 的模式 (高考成绩占 百分之六十, 自主招生考试成绩占百分之三 十, 高中学业成绩占百分之十) 报考我校, 也可以通过提前批报考北师港浸大（考分须 在高优线以上 )。

\section{6. 高品质的教学}

高水平的学生培养是通过课程教学实现 的, 因此高品质的教学是北师港浸大教学质 量保障的最核心的部分。北师港浸大全面实 施了以成效为本的教与学 (OutcomesBased Teaching and Learning [OBTL]) 以 及标准参照的评价模式 (CriterionReferenced Assessment [CRA]) 的教育改 革, 教学过程实现以 “教师授课中心” 到 “学生学习中心”的过渡和转化。通过改 革, 学校课程设计、教学模式、评价标准实 现了与香港乃至国际的接轨, 增强了学校以 及学生的国际竞争力。同时, 在教学过程中 大力调动师生互动积极性, 使师生能随时了 解自己在教与学中所处的阶段和预期目标, 并做到及时调整改进; 促使教师根据学生反 馈的学习需求不断更新教学方法与教学内 容, 从而令课程教学设计更科学, 学生的学 习体验更多元化。

学校采用全英文教学, 为了解决学生间 的英语水平差异问题, 使学生都得到全面的 培养, 英语语言中心采用多维立体的课程设 置。中心按照学生英语学习能力和提升速度 把学生进行分类, 并根据他们所分属的级别 不同订制他们所属的级别英语课程。个别英

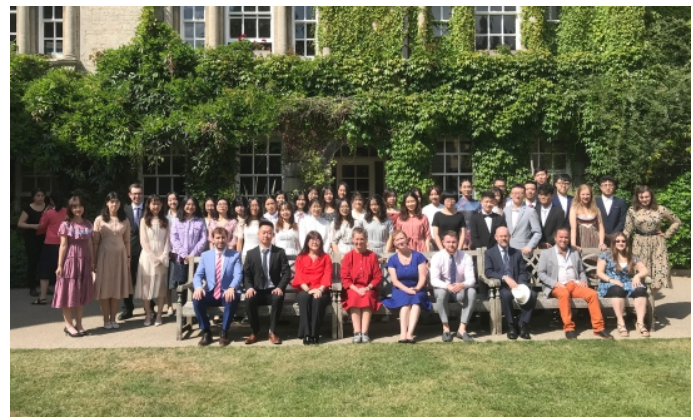

学生参加牛津大学暑期研习项目

语学习遇到障碍的学生可以通过英语语言中 心组织英语俱乐部活动, 以及苗固关顾计 划, 在外籍助教的帮助下跨越障碍, 排除学 习和生活, 乃至心理方面遇到的困难。这些 探索为学生英语学习与提高提供了多种途径 和较大的发展空间。

为了更好地促进每个老师高质量的授 课, 学校每学期末安排全校性的网上教学质 量评估(TLE: Teaching \& Learning Evaluation), 了解学生对教师的教学能力、 态度、责任心及教学方法优劣的看法, 让教 师了解学生的学习成效和反馈, 评判教学成 果是否达到预期学习目标。教师可查看其所 授课程的评估结果, 以便针对学生的意见反 馈作出改进和优化其教学。专业课程主任和 院长亦会对本专业或本学部所有课程的评估 结果进行审阅，与教师共同讨论相关问题以 提高教学质量。教学质量评估年度报告将详 细分析学生反馈, 其后分别呈递予北师港浸 大及香港浸会大学教务议会审阅。同时，评 估结果及教师的反馈将作为教职工绩效评估 参考指标之一。

此外, 为进一步改善教学质量, 各学 部或教学单位会根据本部门情况组织期中教 学评估, 以帮助教师适时调整教学计划, 促 使学生的学习成效达到预期目标。 
为培养学生的国际化视野, 学校还通过 国际交换生项目、国际暑期课程、海外实习 等形式, 使学生对国际上高水平的大学教育 有切身的了解。

创

科学的教学管理是确保教学质量提升的 重要保障。北师港浸大全面实行学分制, 并 采用平均绩点 (GPA) 的办法来评价学生的 总体学习水平。平均绩点是学生成绩的总体 指标, 是体现学生学术表现的重要指标, 是 学生考试获得的所有绩点总和除以所有应获 学分总和所得的结果。学期平均绩点 ( sGPA) 是某学期学生获得的学习成绩; 累计平均绩点 (cGPA) 是学生大学期间, 累计学习成绩的绩点总和除以累计应获学分 总和的结果。平均绩点反映了学生的总体学 业成绩。

为了激发学生的学习积极性, 北师港浸 大的毕业要求和学位证书类别都与 GPA挂 钩。学生毕业如果完成学校课程所要求学 分, 且累计学习成绩 (cGPA) 超过1.67的 学生, 可获得毕业证书; 如果完成学校课程 所要求学分, 且累计学习成绩 (cGPA) 超 过2.0的学生, 可获得学士学位证书; GPA在3.6-4.0之间, 可获得甲等荣誉 (First Class Honours) 学位证书; 如果 GPA在3.0-3.39之间, 学生可获得乙等一级 荣誉 (Second Class Division I Honours) 学位证书; 如果GPA在2.5-2.99之间, 学生 可获得乙等二级荣誉 (Second Class Division II Honours) 学位证书; 如果 GPA在2.20-2.49之间, 学生可获得三等荣 誉 (Third Class Honours) 学位证书; 如果
GPA在2.0-2.19, 学生可获得合格等级 (Pass) 的学位证书。

在学习过程中, 如果某一学生某一学期 平均绩点 (GPA) 在1.67-1.99之间, 则该 同学会受到学术警告一次; 如果某个学生某 一学期的平均绩点 (GPA) 在1.67以下, 则 该同学会被做出留校察看的处理; 如果某个 学生连续两学期的平均绩点 (GPA) 低于 1.67 的学生, 则该学生会受到勒令退学的处 理。当然, 以上处理条款, 通常经由学校教 务议会作出最终决定。

\section{8. 导师关顾计划}

学生是大学教育的核心。关爱学生, 以 学生为本是北师港浸大的重要指导思想。导 师关顾计划就是体现这一思想的制度措施。 导师关顾计划是新生开启与学校联系沟通的 重要渠道, 由导师 (所在专业的老师) 、朋 辈导师 (高年级学生) 和组员 (新生) 三部 分构成, 每个小组约10-20名组员。导师、 朋辈导师对新生的生活、学习、心理、课外 活动等方面给予关怀和辅导, 帮助新生早日 适应学校的国际化教育模式和学习生活环 境。同时导师亦会分享他们的专业知识和宝 贵经验, 培养学生对专业的认识, 以及推动 其个人的成长。

\section{9. 丰富多彩的校园文化}

良好的校园文化不仅可以丰富学生的日 常生活, 而且为学生的学习提供良好文化环 境。北师港浸大非常重视校园文化建设, 不 仅学生自己成立有 60 多个学生兴趣社团（其 
中有20多个特色社团），而且定期开展多种 学术和文化活动。各学部、全人教育办公 室、通识教育办公室、英语语言中心、中国 语言文化中心等机构定期或不定期举办各种 学术活动和文体活动, 四维教育协调处也经 常举办创新创业大赛、高桌晚宴等活动。这 些活动丰富了校园文化, 使学生获得了很多 课堂外的知识和能力。

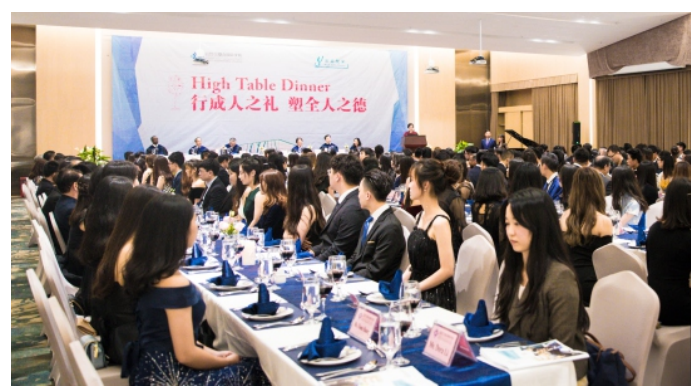

在高桌晚宴上, 学生聆听嘉宾演讲

\section{0. 良好的条件支持}

良好的办学条件是保障人才培养质量的 重要方面。经过14年的发展, 北师港浸大不 仅拥有了一个美丽的校园, 而且办学条件显 著改善。学校拥有藏书( 尤其是外文藏书) 丰富且学习环境良好的图书馆, 拥有先进的 教学实验室, 有先进的电子教学平台, 有良 好的实习基地, 有能容纳千人的大学会堂, 有条件良好的体育馆, 有能举办各种学术和 文艺活动的演艺厅等等。学校的经费也优先 支持教学。

\section{三、外部保障体系}

北师港浸大不仅重视内部质量保障体系 的建设, 而且非常重视外部质量保障的建
设。比如, 两个母体学校会定期对学校整体 的行政与教学质量进行评审; 所有专业的设 立要通过两个母体学校的专业审核; 建立校 外评审官制度, 通过校外评审官对学校的教 学质量提出意见建议; 建立顾问委员会制 度, 让顾问委员会委员对学校的建设做出建 议; 此外, 校友会和家长也对学校的健康发 展提供意见和建议。

\section{1. 两个母体学校对学校整体的行政与教 学的评审}

北师港浸大自创办之初就完整地引入了 香港浸会大学教学质量保障体系, 对教学过 程实行全程监控, 确保卓越的教学效果和质 量。同时, 香港浸会大学作为北师港浸大毕 业生的学位颁授机构, 定期对北师港浸大进 行院校评审, 以确保北师港浸大教学和行政 的有效运作。自2005年北师港浸大建校以来, 至今已进行了六次的审核 (2007年7月, 2008年12月，2010年5月，2011年12月， 2014 年3月，2017年3月）。最新的评审在 2019年的9月启动。

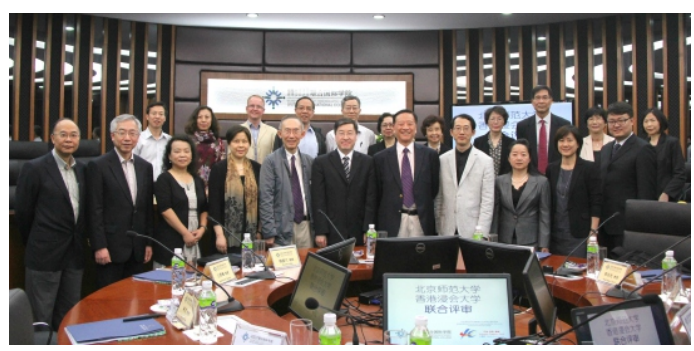

2015年, 北京师范大学与香港浸会大学对 北师港浸大进行联合评审

为了全面有效地审核北师港浸大的教学 质量和行政效益，评审小组由浸大负责质量 
保障的副校长为主席, 其他十多位成员包括 浸大的教务长, 浸大校内和来自海外的资深 学者。评审小组严格按照香港浸会大学学术 与管理的标准, 对北师港浸大的教学与管理 工作进行审查, 以确保学术和管理标准的有

\section{2. 所有专业的设立必须通过母体学校和 教育部的审核}

北师港浸大所有专业的设立除了学校 自己的层层审批之外, 还必须经香港浸会大 学和北京师范大学各自的审批。比如, 我校 理工科技学部成立 “数据科学与大数据技 术”时，香港浸会大学2016年委派六位专 家组成的评审小组, 对理工科技学部的“数 据科学与大数据技术”专业的建设提案进行 了评审。该小组成员包括四位来自香港、台 湾、新加坡的学术专家和两位北师港浸大的 校内专家。

在为期两天半的评审过程中, 评审小 组分别与北师港浸大的校管理层、理工科技 学部院长、专业策划团队、学生、潜在用人 单位等利益相关方进行会晤。同时，评审小 组也对学部师生的科研能力、学术成果以及
该专业为学生提供的学习环境进行了评估。 综合以上各方面的评审结果, 评审小组认为 成立 “数据科学与大数据技术” 专业顺应了 当下中国对数据科学家需求激增的趋势, 也 对该专业清晰的目标设定表示认同, 并认为 数据科学与大数据技术的师资力量、办学条 件等都达到了专业设置的标准。

文化与创意学部筹划音乐表演专业 时, 北京师范大学委派专家小组对音乐表演 专业设置的必要性和学科实力进行了为期两 天的实地考察和评审。专家小组肯定了该专 业设置的必要性, 也肯定了我校在音乐教育 方面已有的成就，同时也对今后专业的建设 提出了中肯的意见和建议。

\section{3. 校外评审官制度}

为保证每个专业的教学水平和成果与香 港浸会大学的教学质量标准保持一致, 北师 港浸大于2007-2008学年建立了校外评审官 (EEs: External Examiners)制度。在每个专业 开设满三年开始, 香港浸会大学将委派教员 担任北师港浸大对应学部、教学部门或者课 程的校外评审官。

校外评审官职责包括：审查教学及评估 材料; 就复核考试评价情况提交书面报告; 就荣誉学位分级的安排及不合格的个案进行 仲裁; 视实际情况, 亲访北师港浸大与师生 直接交流。

经过多年实践, 北师港浸大在学术质量 保障方面取得诸多成果, 获得香港浸会大学 的认可和好评。从2010-2011学年, 校外评 审官制度由“全面审批模式”转为“复核模 式”，即仅对教学考评情况作随机抽查复 核, 并就有关问题提出意见及建议, 北师港 
浸大会做出针对性的回应，以确保教学质量 达到更高的水平。

\section{4. 顾问委员会}

北师港浸大各学部均设立顾问委员会, 由7至15名校内外成员组成。校外成员来自 内地、香港、澳门、台湾等地区的政府和专 业领域, 而校内成员则为学部的教学成员, 且不超过委员会总成员人数的三分之一。为 帮助学部了解社会需求和对学部未来发展做 出规划，顾问委员会每年必须至少召开一次 会议, 内容包括：学部专业的目标、结构和 内容; 与学部相关的研究和咨询活动; 市场 需求和毕业生就业; 学部及各专业的发展和 管理所需的资源，等等。顾问委员会的意见 和建议对学部的了解社会需求、契合国家发 展、提高办学质量具有非常重要的意义。

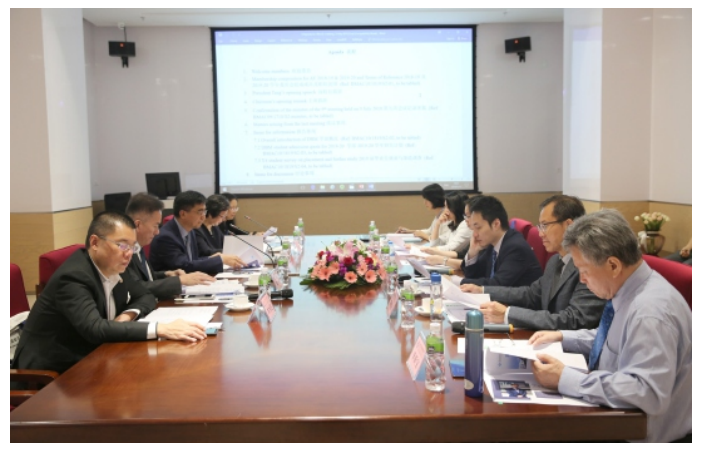

工商管理学部顾问委员会第十次会议

\section{5. 校友及家长联系}

北师港浸大非常重视校友对母校发展的 意见, 学校非常支持校友在各地成立校友

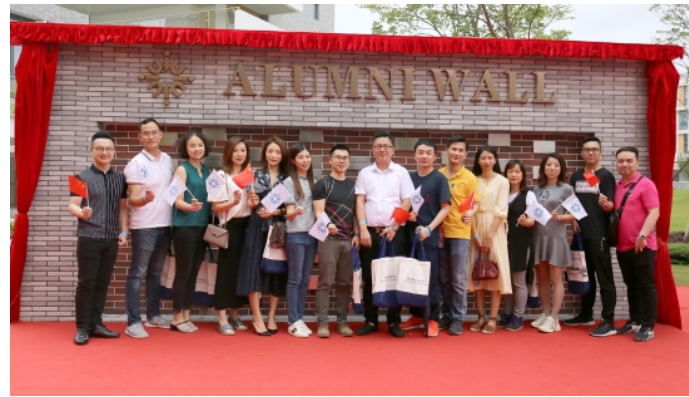

2019年4月27日，北师港浸大第一届毕业 生返校参加“校友回家日”活动

会, 并鼓励校友通过校友会对学校的发展建 言献策。校友会职能主要包括: 增进校友彼 此的联系; 了解校友彼此的动态; 使校友们 悉知母校的发展动向, 为母校的建设和发展 建言献策。

北师港浸大特别强调家庭、社会、学 校、学生四维一体的教育。四维教育中, 家 长是非常重要的一环。为促进家长走进校园 参与学生的教育, 学校专门设立多个平台例 如: 家长网页、新生家长论坛、四维家长通 讯、校长与家长见面会、家长联谊会, 等 等。通过这些平台, 家长和学校密切联系起 来, 家长的意见可通过多种途径反映到学 校, 促进学校教育教学的改革。

\section{四、结语}

卓越的教学质量是北师港浸大一直追求 的目标。北师港浸大过去十多年取得的巨大 成就与其打造的严格的内部和外部质量保障 体系是分不开的。相信在新任校长汤涛院士 的带领下, 北师港浸大能为国家培养出更多 高质量、高层次的精英人才。死 